\title{
Capítulo V \\ La falsa objetividad: el verdadero problema de los medios informativos
}

T a primera idea que quiero exponer antes de comenzar en pleUno este capítulo emerge de la siguiente diferenciación: no es lo mismo comunicar que informar. Resulta muy importante tener presente tal distinción, puesto que la mayoría de discusiones políticas que se escuchan en las universidades, en los pasillos, en las tiendas, en los comedores de las casas, muchas veces se desencadenan por golpes de opinión producidos desde los grandes medios masivos y no propiamente por conclusiones políticas que forjen al menos una conversación medianamente seria, así no sea académica.

Por golpe de opinión se entiende básicamente la emisión de palabras por parte de algún editor, periodista o personaje público, y que viaja por medio de los canales masivos de información al grueso de la sociedad provocando debates, menciones, foros, etc. Frente a este particular, en un anterior capítulo había aclarado que no cualquier opinión produce un golpe de opinión. Por lo tanto, volviendo a la distinción, al pretender hablar sobre política con un individuo que tan solo está informado y, además, parcialmente informado, lo más lógico es que no se esté hablando de política, sino de la repetición de un mensaje que no se comprende, pero en el que se cree con fe. Aquí debo hacer un alto y recordar que una de las condiciones básicas para hablar de política en Colombia es 
que como mínimo el diálogo realizado contenga argumentos, ya que, aunque no se trata de demeritar los actos de fe, en política resulta más prudente y coherente dialogar en torno a argumentos con el fin de evitar odios infundados, que producen fundamentalismos y estos, a su vez, violencia.

En Colombia, el papel de los grandes medios ha sido el de informar, no el de comunicar; por este motivo, se ha degradado la compresión de la historia, el abordaje de procesos políticos, la profundización en sus causas, o en cómo se constituye la opinión. Así mismo, han resultado un conjunto de ciudadanos, una partida de adictos a la información, que construyen su opinión política a partir de banalidades, lo que finalmente termina configurando artefactos desprovistos de sentido común y "ultracargados" de interés privado, con lo cual el ciudadano, sin querer queriendo, se convierte en una cuña publicitaria de dichos canales.

Ante esta primera tesis, emerge consiguientemente una pregunta evidente: bueno y si lo que hacen los medios en Colombia no es comunicar sino informar, ¿qué es comunicar? en palabras más conceptuales, ¿qué es comunicación?

"La comunicación es el proceso de interacción social democrática que se basa sobre el intercambio de símbolos por los cuales los seres humanos comparten voluntariamente sus experiencias bajo condiciones de acceso libre e igualitario, diálogo y participación" (Beltrán, 2005, p. 21). Esta cita se encuentra inscrita en lo que también se ha denominado la comunicación horizontal, es decir lo opuesto a informar. ¿Entonces qué es informar? Informar se encuentra en el plano de la comprensión clásica de modelo comunicativo:

[...] nacido a fines de los años 40 en Estados Unidos con el esquema de Harold Lasswell ('Quién dice qué en cuál canal a quién y con qué efecto?'), fue refinado y expandido a mediados de los años 60 por Wilbur Schramm y David Berlo ('Fuente-Mensaje-Canal-Receptor-Efecto'). Lo criticaron por percibir 
la comunicación como un proceso unidireccional (monológico) y vertical (impositivo) de transmisión de mensajes de fuentes activas a receptores pasivos sobre cuya conducta ellas ejercen así presión persuasiva para asegurar el logro de los efectos que buscan. (Beltrán, 2005, p. 19)

Según la definición, este modelo clásico de comprensión de la comunicación, o de comunicación vertical, solicita receptores pasivos puesto que ellos son el insumo necesario para asegurar el logro de una posición editorial, política, partidista, en definitiva, privada. ¿Le parece que ya existe una coincidencia con nuestra realidad? Bien, aunque es prematuro comenzar las conclusiones, resulta primordial, basándome en la anterior definición, afirmar que las posiciones de los medios privados masivos de radio y televisión son posiciones verticales, por consiguiente, de interés individual y no colectivo.

No es nada fácil afirmar esto, cuando lo primero que podría decir un dueño o editor de algún canal masivo, es que estoy atentando contra su libertad de expresión, o incluso, algún seguidor fiel de dichos canales podría dudar sobre si existe un interés individual en ofrecer tanto entretenimiento a la gente.

En el caso del seguidor fiel, diría que precisamente el entretenimiento y la información son una fórmula exquisita para asegurar el efecto de una posición política individual y no colectiva ¿O acaso el canal que nos da novelas, reality shows, que salta y grita con nosotros tres horas antes de cada partido de la selección y nos hace olvidar que el país se cae a pedazos tendría la intención de dañarme o convencernos de algo, o hacernos olvidar de algo? (la respuesta se la dejo al lector).

En el caso del editor que revirara por su libertad de expresión, me protejo mencionando que la libertad de expresión no está en juego, no la cuestiono, no la ataco, de hecho, la defiendo, a saber: una cosa es tener el derecho a utilizar un noticiero para decir lo que a juicio del dueño o del editor parezca, y otra muy diferente 
es asegurar que el discurso de un canal o de un editor es una realidad objetiva, es la opinión pública o un discurso neutral.

No es posible que con el sistema comunicativo vertical que existe en Colombia, en el cual unos pocos canales y emisoras masivas manejan la opinión y percepción general, se pueda hablar de realidad objetiva.

¿Podemos hablar de libertad de expresión? Por supuesto que sí. $\mathrm{Al}$ respecto, considero que más de un crítico de los medios masivos está desenfocado, pues los dueños y sus editores pueden utilizar los medios para decir, apoyar o atacar a quien quieran. ¿Le parece terrible esto? Bueno, así es. ¿Le parece terrible que sean masivos? Bueno, es que hasta eso está blindado por la Constitución Política de Colombia en su artículo 20, así que la configuración de una crítica a los medios y esa comunicación vertical que promueven no debe pasar por el tema de la libertad de expresión, sino por la necesidad imperante de desmitificar su supuesta objetividad, jesa es la cuestión! ¿De qué sirve censurarlos? Eso tan solo provocaría que se volvieran más fuertes. ¿De qué sirve decir que mienten? ¡Ellos no mienten! tan solo dan una versión de la realidad, ponen los micrófonos a quien les parece, ubican la cámara como les parece y eso no es ilegal, es antiético, jeso sí! Pero no ilegal, y como en Colombia la ley a veces parece una república independiente, pues desde allí es que se sientan comodísimos a establecer su visión como la única visión, como la realidad objetiva, y convencer incautos, de que hablan desde el altar inexistente, de la neutralidad.

La comprensión de lo anterior es una condición básica para hablar de política en Colombia, porque en ocasiones podría estar estableciéndose un hueco teórico hondísimo al basar una conversación sobre los problemas políticos teniendo únicamente como fuente las posiciones editoriales de un par de medios masivos de información.

La falsa objetividad de los medios informativos debe ser expuesta como uno de los graves problemas que afecta la posibilidad de construir un proyecto político auténticamente desde la 
sociedad, sin injerencia mediática. Correlativamente, como una condición básica para hablar de política en Colombia, se debería tener en cuenta que, desde los medios masivos informativos, se manejan posiciones privadas que responden a intereses particulares que necesitan mantener estilos editoriales para protegerse, atacar o permanecer como amos indiscutibles de la opinión en favor de conglomerados económicos o políticos.

¿Acaso es malo tener posiciones editoriales? Por supuesto que no. Lo que sí es malo, perverso, absurdo y altamente problemático es que un ciudadano promedio, forje una opinión política a partir de lo que exclusivamente anuncian todos los días, en la mañana, al medio día y en la noche, este grupo de medios; eso es pretender forjar una posición política desde la unilateralidad del discurso. Allí sin duda alguna, es donde se elimina toda condición racional y productiva para la constitución de un diálogo político.

Cuando un par de ciudadanos discuten basados en una posición editorial sin comprender las causas de un fenómeno, lo que se produce no son discusiones políticas o sobre política, sino un cúmulo de ideas vacías o discusiones sobre temas en los que se vincula la gente, sin preguntarse, ¿'y por qué tenemos que discutir sobre eso y no sobre otro tema? Si esa simple pregunta emergiera entre la gente, la respuesta pensada, analítica y profundizada, probablemente llevaría a la persona a concluir que hay temas que son muchos más importantes y no se tocan, "por alguna misteriosa razón".

Por lo general, cuando se llama la atención desde una posición crítica sobre un debate o temática que los grandes medios informativos dan por hecho o simplemente se menciona la frase "no estoy de acuerdo" a quien lo está narrando escuetamente, lo que a veces sucede es que aceleradamente, en cuestión de un par de comentarios, emergen discursos rabiosos, en ocasiones deformados por groserías, disgustos, abandono de recintos etc., esto sin duda, degenera la probabilidad de un diálogo político, es un ciclo vicioso constituido por el hecho de que personas comunes repitan 
posiciones editoriales fabricadas por sujetos ajenos a su realidad, posiciones editoriales que no son comprendidas profundamente pero que incluso pueden orientar a las personas a pelear o discutir sin fundamento.

¡Esto se me hace preocupante! pues he tenido que ver a estudiantes que pelean sin fundamento o profesores que abandonan los recintos y no quieren siquiera discutir... A decir verdad, con una exhalación desde una profunda convicción pedagógica, creo definitivamente que la comunicación vertical debe ser identificada y desenmascarada como una condición básica para hablar de política; cuando esto ocurra, coherentemente, se podrá hablar de un proceso del cual cada sujeto será su propio redentor: liberarse de los medios de información.

Ahora bien, definidos ambos tipos de comunicación, ¿en qué consiste entonces el proceso de la comunicación horizontal? o lo que he denominado liberarse de los medios de información. Bien, en la figura 2 expongo una propuesta comprensiva encaminada a que un sujeto cualquiera defina su proceso de liberación.

Figura 2. Esquema horizontal de comunicación

\section{Realidad en la que están contenidos A y B}

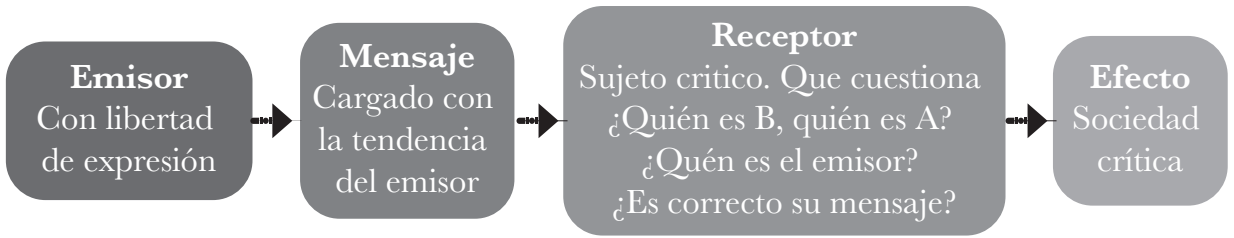

Fuente: elaboración propia.

A diferencia de ese ciclo de la información que he sustentado en el capítulo III, la anterior figura presenta de manera abstracta la posibilidad de acercarnos al insumo más valioso para el diálogo: conocer. 
Un acercamiento a ese conocer puede darse mediante el proceso de la comunicación horizontal. Este esquema presenta inicialmente a la realidad como un elemento objetivo, sujeto de análisis multilateral. No obstante, para efectos de la explicación del esquema, se considerará la existencia de un emisor y un receptor cualquiera.

Entonces, en primer lugar, se da por hecho la existencia de un emisor que puede opinar lo que desee en el marco jurídico de la libertad de expresión. En segundo lugar, dicho emisor provee un mensaje que por supuesto tiene implícita una subjetividad que se materializa bien sea con una posición editorial o con atributos discursivos con características de beneplácito o de contradicción hacia una situación política o no.

Hasta este punto, el mensaje es unilateral porque un emisor, concretamente un emisor que emplea un medio informativo, lo emplea como canal o instrumento comunicativo unidireccional llámese televisor, radio, redes sociales o página web. Respecto de estos instrumentos comunicativos, vale la pena anotar que la televisión y la radio llevan la ventaja unidireccional, porque los televidentes y los oyentes pueden aprobar o desaprobar lo que ven y escuchan, pero en un total y vacío anonimato... ¿Acaso no recordamos ya a un familiar o incluso a nosotros mismos, alegando frente al televisor como si este pudiese escucharnos?

Por su parte, en las redes sociales y la página web las audiencias pueden comentar, dar un "me gusta", insultar o apoyar si se ha habilitado un espacio para ello. Empero, cuando uno lee comentarios en las noticias virtuales de cualquier portal de información masiva, se da cuenta de que la opinión de esos ciudadanos es tan vacía como los comentarios anónimos de televidentes y oyentes, no por su contenido formal o gramatical en sí, sino por el significado que tiene frente a la construcción de la nota informativa. En otras palabras, que opinemos o nos agarremos a groserías en el espacio para comentarios de una noticia en una página web o red social, no influye para nada en la posición editorial, es más, ocurre algo 
a mi juicio grave, y es que se da por hecho que el consenso de la discusión fue bien dado por quien redactó. Lo anterior resulta en que la gente discute por cosas que no van a la raíz de los problemas, nuevamente: artefactos desprovistos de sentido.

Finalmente, en tercer lugar, teniendo en cuenta la figura 2, aparece el sujeto receptor que podría no aceptar directamente el mensaje que presenta un receptor, tan solo bajo la premisa de cuestionar ¿quién es el receptor? Y con esto no me refiero a la joven o el joven que en ocasiones no lee bien el telepronter, sino a quien, por ejemplo, sale favorecido con ese mensaje. Cuando el sujeto receptor cuestiona el mensaje preguntándose otras formas de comprender la realidad que se le está presentando como objetiva, en esencia, equivaldría a preguntarse "¿qué dicen otros emisores frente al mismo caso expuesto en un mensaje?”. En este punto el receptor dará cuenta de las múltiples opciones comprensivas y obtendrá como resultado un criterio construido multilateralmente. El efecto es sin duda, un sujeto crítico y, extensivamente, una sociedad crítica.

En el marco de la explicación de la figura 2 el lector puede estar percibiendo una gran preocupación por la comprensión de los discursos como un insumo básico para hablar de política; en efecto, puede surgir el siguiente interrogante: ¿por qué delegar tanta importancia a la composición de un criterio político desde la multilateralidad discursiva?

En principio, porque la sociedad contemporánea está atravesada discursivamente por posiciones editoriales que sustentan la opinión general y emplean los medios masivos de información para constituir un sentido común sobre la percepción de los hechos, que en el orden de lo que vengo argumentando, no es más sino un interés individual, transformado en sentido común.

A propósito de lo anterior, no es un secreto lo que hemos escuchado hablar a estudiantes y docentes, sobre uno de los tantos terribles problemas de la sociedad colombiana, ese que denuncia la falta de hábitos de lectura, la superficialidad de lo mediático 
etc., frases vehementes como "ipero es que la gente no lee!" constituyen no solo una expresión sino un lugar común entre muchos sectores. Quisiera afirmar que dicho "lugar común” no está lejos de un marco de veracidad comprobada. A continuación, con las cifras ofrecidas por el Centro Regional para el Fomento del Libro en América Latina y el Caribe (CERLALC), podemos hacernos una idea comparativa desde un punto de vista sustentado por la estadística (figura 3).

Ese $63 \%$ de hogares en Colombia que tienen más de cincuenta libros en la casa contrasta penosamente con el dato de los libros leídos por año. Se podría concluir algo así como que cada casa en Colombia tiene una biblioteca, pero constituye más una pretensión intelectual, o una obligación decorativa, que un sentido tácito de la apropiación del hábito de la lectura; incluso, es probable que el lector en este punto del libro ya no me esté leyendo, porque hay una costumbre coloquial (sujeta a comprobación empírica) que indica que de todos esos libros que comenzamos, al final nunca los terminamos, tal vez por eso, sociológicamente, y con intuición pedagógica, he constituido los capítulos más extensos al principio, pues son el argumento base para los capítulos concluyentes.

Recapitulando, los datos estadísticos de la GERLALC siguen apoyando mi argumento, de que en Colombia se lee poco. Queremos todo rápido, fácil, el resumen del resumen. En nuestras calles, los periódicos ya ni siquiera hay que comprarlos, los regalan, con instantáneas informativas que siguen promoviendo debates superfluos entre los ciudadanos y, por consiguiente, de acuerdo con lo que he planteado hasta este punto: discursos políticos vacíos, a la par de vociferaciones cargadas de amores y odios ciegos que gestan poco a poco en Colombia un marco para el fundamentalismo político. 


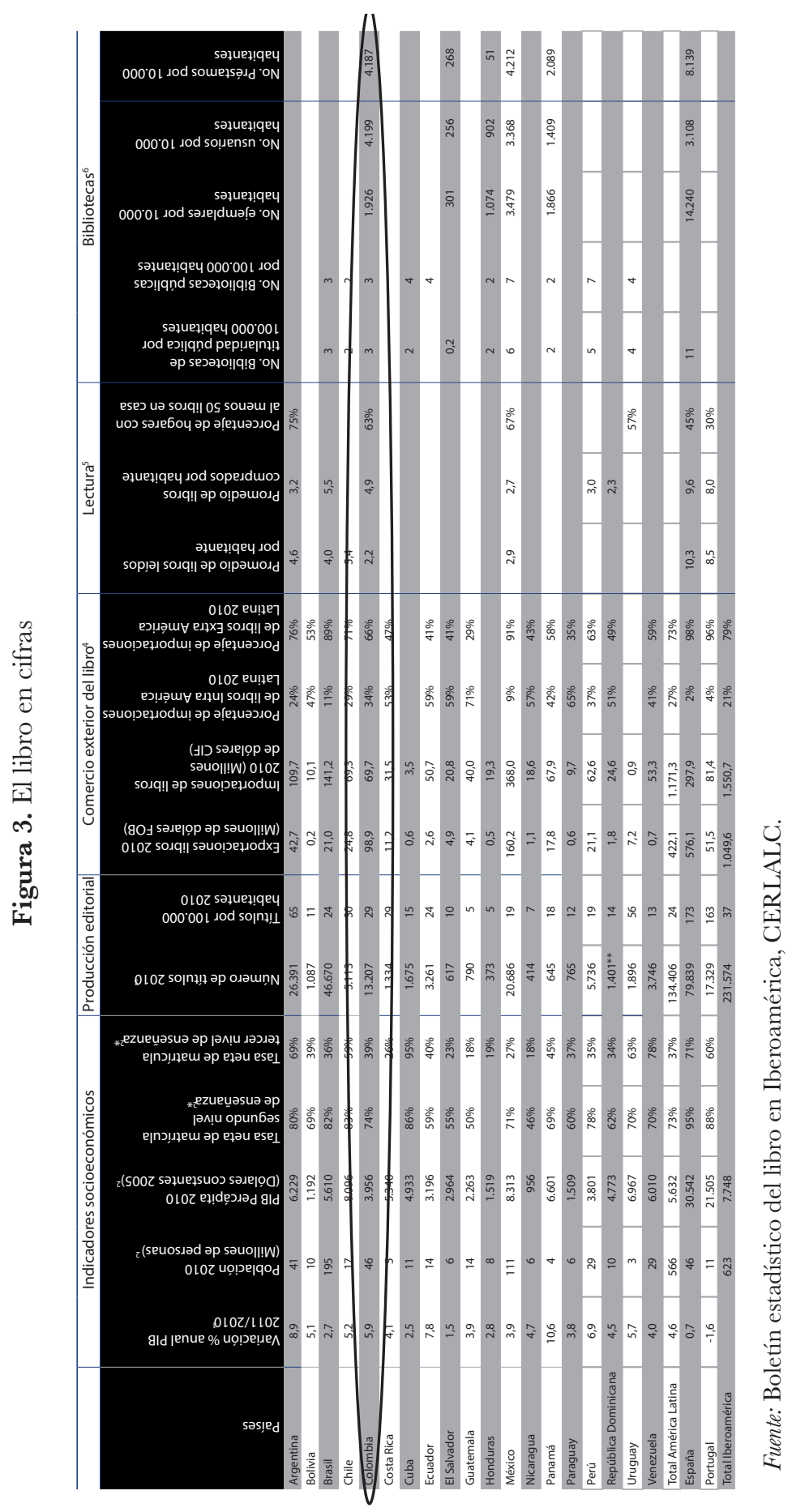

124 Condiciones básicas para hablar de política en COlOMBIA. 
Por esta razón emergió la necesidad de este capítulo, porque cuando damos cuenta de la importancia que tiene identificar la forma de comunicación que está viajando más rápido que el esfuerzo académico, entonces pasan por la cabeza de cualquier pedagogo las intenciones de impulsar o dejar de lado el ego academicista, la ingenuidad discursiva y pasar al hecho de combatir la maña de explicar los problemas del país desde posiciones inentendibles, pues así lo único que se ha logrado es que el debate se eleve hasta las nubes más inalcanzables para aquellos implicados y necesitados de una explicación, que por lo general, se movilizan a pie y no entre nubes.

La importancia de la constitución multilateral de un criterio político no solo es un mensaje que se vislumbra como esfuerzo de las mejores conclusiones académicas, sino que constituye absolutamente una forma de resistencia operativa y discursiva contra esa comunicación vertical que he descrito anteriormente.

Operativamente, desmantelar la comunicación vertical que promueven sobre todo los medios de información masivos funciona como punta de lanza contra el determinismo, esa vieja y mala costumbre de encasillar y por ende demeritar cualquier opción entendible de las problemáticas que en resumidas cuentas no salgan por los canales mediáticos acostumbrados. Operativamente, desmantelar la comunicación vertical para así darle un escenario a las condiciones básicas para hablar de política, significa que bajo efectos conscientes, se hará de lado, por lo menos por un instante, el debate sobre la libertad de expresión y nos concentraremos en el problema tan fastidioso y delicado que implica conceder a uno o tres noticieros la autoridad narrativa de la realidad política; es decir, para desmantelar la comunicación vertical se debe debatir la supuesta neutralidad discursiva con la que muchos medios informativos se presentan ante la sociedad... ¿Y la libertad de expresión? A decir verdad, si lográramos configurar una sociedad crítica que reconoce la probabilidad de un mensaje incompleto o 
manipulado ¿acaso importa que un medio informativo hable superficialidades? La respuesta se la dejo al lector.

Como lectores, podemos permanecer en la suspensión del texto. Tratarlo como texto sin mundo y sin autor y explicarlo entonces, por sus relaciones internas, por su estructura. $\mathrm{O}$ bien podemos levantar la suspensión del texto, acabar el texto en palabras y restituirlo a la comunicación viva, con lo cual interpretamos. Estas dos posibilidades pertenecen ambas a la lectura y la lectura es la dialéctica de estas dos actitudes. (Ricoeur, 2002, p. 135)

Esa comunicación viva que nos recuerda Ricoeur es precisamente la construcción del discurso, del diálogo que resiste a la comunicación vertical. Hoy, por ejemplo, se naturaliza el hecho de la conversación virtual a través de los medios tecnológicos que impulsan las redes sociales; es claro que para algunos sectores, las redes sociales son sinónimo de aislamiento; no obstante, la mayoría de esos sectores no da mérito a las redes sociales y las maneras en que han facilitado el acercamiento (como condición mínima para el diálogo), sino que se limitan a la crítica de las conversaciones virtuales, de las redes, tildándolas de "antinaturales" cuando son manifiestamente un fenómeno comprobado, inserto sociológicamente en las formas de comunicación social contemporánea.

Ricoeur con la comunicación viva, se convierte en una opción para comprender el efecto perjudicial de una comunicación vertical, ¿perjudicial para quién? preguntará el lector; evidentemente, para la probabilidad de tener un diálogo que conduzca a una conclusión o desacuerdo político, pues tanto la conclusión como el desacuerdo son parte de la política. Lo que no es parte de la política son esos artefactos desprovistos de sentido o "rifirrafes" que se dan entre ciudadanos que hablan solo bajo el conocimiento de una información superflua sobre una situación que acontece en el país.

"Aquellos que, mientras desaprueban el carácter y la necesidad de determinado gobierno, le conceden su adhesión y sostén, 
son indudablemente sus más concienzudos paladines; y así, a menudo, el obstáculo más difícil para la reforma" (Thoreau, 1980, p. 24). Citar a Thoreau en medio de una discusión planteada sobre la comunicación, los medios, las redes sociales, puede parecer descabellado, atemporal, desproporcionado, etc. No obstante, ¿acaso Colombia no pervive su contemporaneidad en medio de las causas y razones problémicas más atemporales que podamos imaginar? Bien, las palabras de Thoreau son una piedra angular en la comprensión profunda de la relación entre ciudadanos y medios masivos de información actualmente, pues existen muchos ciudadanos que en realidad ni les importa qué o cómo se presenta la información sobre la realidad del país, viven desconectados incluso de la posibilidad de una charla política. No obstante, apelo a la discusión y al debate sobre dicha relación, porque a pesar de que exista esa gran masa de gente que puede ignorar tanto una noticia bien elaborada como una noticia superflua, por uno u otro motivo, terminan directa o indirectamente, afectada o beneficiada, por una situación política subyacente o inmanente a su interés por comprender. En otras palabras, por más de que exista ese grueso movimiento que he denominado en mis cátedras como el nimierdismo ${ }^{1}$, en Colombia la relación ciudadanos-medios informativos masivos tal como está planteada hoy, de esa forma vertical y subjetiva, solicita gente que hable de "política" como algo parecido a una caja repetidora de una posición editorial. Y si bien eso no es ser "concienzudo" en los términos que está expresando Thoreau, por lo menos sí es el paladín por antonomasia de los artefactos

1 En mis cátedras, en forma satírica y preocupada, he denominado a las personas que no les importa la política, ni la academia, ni la naturaleza, ni sus relaciones con los demás, ni la reflexión, ni básicamente nada más que no sea dinero para consumir autómatamente y vivir creyendo que el mundo comenzó con ellos y termina con ellos, como nimierdistas. Y por ende, todas sus derivaciones metalingüísticas. 
desprovistos de sentido, que en últimas son los obstáculos más grandes para hablar de política en Colombia.

En conclusión, la falsa objetividad es el verdadero problema de los medios de información porque sus editores, sus dueños, se están excluyendo de un debate político que están orientando tras bambalinas. Insisto, la libertad de expresión no es un problema per se a la hora de abordar la temática sobre, por ejemplo, las responsabilidades que las grandes cadenas mediáticas tienen en los fenómenos políticos o la conducción sesgada que realizan a la percepción de las personas sobre un fenómeno, incluso, muchas veces cuando tímidamente algún político en Colombia las critica o las señala, casi ipso facto sus escuderos reaccionan ofuscados exigiendo que no se les persiga o que se les respete su libertad de expresión.

Ahora que finalizo el presente capítulo, en el marco del típico encasillamiento del que he hablado y que persiste en Colombia, puede que el lector esté determinando la existencia en mi ser de un "odio" hacia los medios masivos de información. Si eso es así, entonces no se ha comprendido el mensaje. Mi mensaje lo puedo resumir diciendo que los medios masivos informativos son usados por sus dueños y por sus editores como ellos quieren y prefieren, que lo anterior no constituye una ilegalidad, ni una mentira en el sentido tácito de la palabra, lo que sí constituye, sin duda, es una comunicación de tipo vertical y esta es una negación del diálogo político. Además, sus productos no pueden ser considerados una realidad objetiva, puesto que los fenómenos políticos solicitan análisis y narraciones desde diferentes perspectivas, en apreciaciones y sobre todo en consensos sobre los debates o preguntas que se construyen como "válidas" o "pertinentes" pues fácilmente diría alguien "pero en x o y medio hablan con todo el mundo" a lo cual tendría que responder en el marco de lo que vengo explicando que así hablen con todo el mundo, los cierres editoriales (sin ser esto un secreto para nadie) dejan bien parados a unos y desacreditados a otros según la conveniencia, es decir el interés individual del dueño 
del medio informativo. Los fenómenos políticos solicitan ante todo comunicación horizontal, una conversación, y aquí vale la pena mencionar una conclusión de Gadamer:

Todo hablar dirigido al otro -al presente, ausente, determinado o indeterminado-, sea en forma de pregunta sea en forma de respuesta, es al fin y al cabo consciente de que no ha dicho lo que en realidad hubiera querido decir. Solo en esas ocasiones felices en que se logra verdaderamente una conversación, donde el otro nos sale al encuentro y corresponde realmente, todo intento pasa del fracaso al logro. (Gadamer, 1998, p. 35)

Esas ocasiones felices a las que se refiere el autor alemán son la esencia de la comunicación horizontal, salir al encuentro del otro y corresponder, salir al encuentro del otro y escuchar, comprender, más allá del discurso emitido desde un medio informativo que puede generar más o menos una percepción, pero nunca aquello que he denominado el conocer. En efecto, derrumbar la información como esa torre de babel de la que se sirven muchos para odiar sin fundamento o amar sin convicción es también una condición básica para hablar de política en Colombia. 
